\title{
Lexis
}

Journal in English Lexicology

13 | 2019

Lexicon, Sensations, Perceptions and Emotions

\section{Conjuring up terror and tears: the evocative and persuasive power of loaded words in the political discourse on drug reform}

\section{Sarah Bourse}

\section{OpenEdition}

Journals

Electronic version

URL: http://journals.openedition.org/lexis/3182

DOI: $10.4000 /$ lexis.3182

ISSN: 1951-6215

Publisher

Université Jean Moulin - Lyon 3

\section{Electronic reference}

Sarah Bourse, "Conjuring up terror and tears: the evocative and persuasive power of loaded words in the political discourse on drug reform », Lexis [Online], 13 | 2019, Online since 14 March 2019,

connection on 20 April 2019. URL : http://journals.openedition.org/lexis/3182 ; DOI : 10.4000/ lexis.3182

This text was automatically generated on 20 April 2019.

\section{(c) (i) (9)}

Lexis is licensed under a Creative Commons Attribution-NonCommercial-NoDerivatives 4.0 International License. 


\title{
Conjuring up terror and tears: the evocative and persuasive power of loaded words in the political discourse on drug reform
}

\author{
Sarah Bourse
}

\section{Introduction}

1 In the last few years, the use of the adjective "post-truth" has been emerging in the media to describe the political scene. This concept has gained momentum in the midst of fake allegations during the Brexit vote and the 2016 American presidential election, so much so that The Oxford Dictionary elected it word of the year in 2016. Formerly referring to the lies at the core of political scandals ${ }^{1}$, the term "post-truth" now describes a situation where the objective facts have far less importance and impact than appeals to emotion and personal belief in order to influence public opinion ${ }^{2}$.

2 This sudden increase in the use of the term "post-truth" and the branding of our modern age as a "post-truth era" lead us to the following questions: to what extent can this prevalence of emotions be observed in recent political speeches? What are the emotions to which speakers tend to appeal? What are the strategies used by the speakers in order to persuade the audience? More precisely, to what extent is the lexicon used in political speeches prone to arouse emotions?

As Charaudeau argues, "the use of words or iconic features does not necessarily constitute evidence for the existence of an emotion." (Charaudeau [2008:51, my translation]) and he also underlines that the use of words such as "anger," "horror," or "anguish" might even be counterproductive, emotion being more a matter of feeling " ressenti") than a matter of words. If these words seem to be easily dismissed, is it possible to identify any other lexical units that could provoke emotions? Furthermore, communication being a matter of co-construction, the potential "pathemic effects," as 
Charaudeau calls them, are also subject to the perception of the audience and their collective representations. Therefore, a careful study of persuasive strategies should not fail to address the audience's expectations, prior knowledge, representations and stereotypes.

In order to study the role played by the lexicon in appeals to emotion, I shall focus on the question of drug reform in the United States. The topic of drug reform encompasses questions such as the legalization of marijuana and the recent opioid crisis and it represents a major health issue that has been the focus of many debates. It is a multifaceted issue as it has economic, medical as well as criminal implications.

5 The present paper is organized as follows: I shall first describe the theoretical framework on which this study is based and provide a working definition for the key-terms. I shall then present the analysis performed on the corpus under study, by first providing an overview of the lexical patterns identified in the corpus, and secondly examining specific examples in context to show the role played by lexicon in the persuasive strategies carried out by politicians.

\section{Theoretical framework and definitions of key-terms}

6 In this first part, some theoretical backgrounds and methodological tools useful for the analysis will be presented. Anscombre's theory of topoi [1995a, 1995b] can shed light on the argumentative dimension of emotionally-charged lexicon, while frame semantics [Fillmore 1977, Fillmore \& Atkins 1992] may provide a complementary view, showing how lexicon can activate a frame; both theories providing a way to access the expectations and conceptual representations of the audience, which are crucial when examining pathemic effects. A third theoretical background that may be of interest for this study is Lakoff and Johnson's Conceptual Metaphor Theory [1980], as political discourse is overflowing with metaphors. In this first part, I shall also define the terms central to the study, such as "emotion," "feelings," and other related terms, as well as explain what is meant by the expression "loaded words."

\subsection{Anscombre's theory of topoi}

7 Anscombre's theory of topoi seems relevant to study the role of the lexicon in argumentation because it posits that language is fundamentally argumentative, not only at the sentential level but also at the lexical level. With each word is associated a topos that serves as warrant for the link between the argument and the argumentative conclusion. The topos is better described as a "path of inference" (Macagno \& Walton [2010: 1999]) and can be illustrated thanks to the following examples: "The weather is beautiful so we should go for a stroll." (Anscombre [1995b]), or "The more you work, the more you succeed." (Anscombre et Ducrot [1980]). As a consequence, "the meaning of a word is nothing more than a set of topoi associated with this word" (Anscombre [1995b: 191, my translation ${ }^{3}$ ]).

Seeing that the theory of topoi contains some inconsistencies and limits, Anscombre has since offered a new framework, the theory of stereotypes, based on Putnam's and Fradin's posits on stereotypes (Anscombre [2001]). The stereotype of a term is defined as "an open set of sentences associated with this term, and defining its signification." (Anscombre 
[2001: 60, my translation $\left.{ }^{4}\right]$ ). These stereotypes are determined by linguistic communities and form an open-ended list. A linguistic community is defined as "any set of speakers that is presented as sharing (among other things) a certain list of terms assigned with the same significations." (Anscombre [2001: 60, my translation $\left.{ }^{5}\right]$ ).

The theoretical framework of Frame Semantics also addresses the expectations of a linguistic community through lexicon but offers a different view of lexicon as it is a cognitive theory.

\subsection{Frame Semantics}

Fillmore \& Atkins stress the central role of experience in understanding:

[In s]emantic theories founded on the notion of cognitive frames or knowledge schemata, [...] a word's meaning can be understood only with reference to a structured background of experience, beliefs, or practices, constituting a kind of conceptual prerequisite for understanding the meaning. (Fillmore \& Atkins [1992: 76-77])

In the theory of Frame Semantics, the meaning of words can thus be understood on the basis of a semantic frame. A frame refers to a network of semantic aspects not contained in the definition of a word (such as the type of event, relation and participants involved in $i^{6}{ }^{6}$. Accounting for the frame a lexical unit (LU) can activate allows tackling not only how this LU is used by the speaker but also how the LU can be understood by the addressee (reception).

Frames are also described as "structures of expectations" (Tannen [1979: 138]). Tannen actually borrows the expression from R.N. Ross [1975] and she defines them as follows:

Based on one's experience of the world in a given culture (or combination of cultures), one organizes knowledge about the world and uses this knowledge to predict interpretations and relationships regarding new information, events, and experiences. (Tannen [1979: 138-139])

This definition shows the relevance of prior knowledge in the treatment of new information.

Identifying the expectations of the audience appears as a key element when trying to shape relevant and effective appeals to emotion. Very simply said, if the speaker understands what makes the audience tick, s/he can then form an effective argumentative strategy by pushing the right buttons. From the point of view of the linguistic analysis, it is crucial to dissect the rhetoric strategies used by politicians and Frame Semantics provides a relevant framework to do so.

Lakoff and Johnson's Conceptual Metaphor Theory (hereafter CMT) also offers a relevant framework to study conceptual representations through the prism of metaphors.

\subsection{Lakoff and Johnson's Conceptual Metaphor Theory}

15 Central to Lakoff and Johnson's theory is the claim that "our ordinary conceptual system [...] is fundamentally metaphorical in nature." (Lakoff \& Johnson [1980: 3]). Metaphors thus govern the way we perceive the world but also the way we behave and interact in the world. As such, they play a considerable role in the representation of truth and reality. Metaphors instill a particular vision of the target domain: 
New metaphors, like conventional metaphors, can have the power to define reality. They do this through a coherent network of entailments that highlight some features of reality and hide others. (Lakoff \& Johnson [1980: 157]) where some aspects of this phenomenon are foregrounded while others are downplayed, and as a result, they prove to be a very effective device in argumentation:

In most cases, what is at issue is not the truth or falsity of a metaphor but the perceptions and inferences that follow from it and the actions that are sanctioned by it. (Lakoff \& Johnson [1980: 158])

The entailments underlying the metaphors are of crucial importance when studying argumentation and persuasion. In fact, what metaphors convey is comparable to the effect of the "begging the question" argument scheme: by using a metaphor, the speaker gets the audience to accept a conclusion for which no evidence has been given.

According to the aforementioned theories, the two cognitive theories emphasize the central role of experience in the conceptualization of the world and its function in understanding. The notions of expectations, underlying background knowledge, and experience seem to be essential to understand the speaker's goals and the intended reception of the speech. Anscombre's theory of topoi and theory of stereotypes tackle the issue of lexicon, positing that language is fundamentally argumentative and topoi form part of the meaning of words.

These three theoretical frameworks thus highlight, in different ways, the fundamental role that inferences play in persuasive strategies.

\subsection{Definitions of the key-terms}

\subsection{1. "Emotions," "feelings," and other related terms}

20 The term "emotion" refers to a mental state associated with bodily reactions. In other words, the arousal of emotion in an individual involves cognitive and physiological changes. The components of emotion include the experiencer (the one who undergoes the emotion), the stimulus (that which provokes emotion), and the response (the state provoked by the stimulus). The long-standing debates on emotion bear on how to tell apart different emotions, the relation between emotions and rationality, and the intentionality of emotions (Stanford Encylopedia of Philosophy, hereafter SEP).

In ordinary language, the term "emotion" is used interchangeably with "feeling." However, in many theories, whether in psychology or philosophy, these terms refer to two distinct concepts (SEP). More commonly, "feeling" is used to refer to bodily sensations such as touch, pain, or heat (Oxford English Dictionary, hereafter OED).

The term "sentiment" is more commonly used as a synonym of "opinion" ("What one feels with regard to something; mental attitude (of approval or disapproval, etc.; an opinion or view to what is right or agreeable." (OED)). This term can sometimes be used as a synonym of "emotion," yet with a narrower domain of application ("Now chiefly applied, and by psychologists sometimes restricted, to those feelings which involve an intellectual element or are concerned with ideal objects." (OED)).

In rhetoric and argumentation studies, there seems to be a consensus over the term "emotion" as the use of the expressions "appeal to emotion" and "emotive language" demonstrates. Even though living beings can experience a wide range of emotions, and 
sometimes struggle to characterize them, emotions are usually identified and categorized. The category of "emotions" generally subsumes: pleasure, grief, hope, fear, outrage, anger, pity, and happiness, to quite a few examples, while it excludes depression and elation (those being categorized as "moods," SEP). There have been several attempts to classify emotions. One well-known categorization in the field of psychology is the wheel of emotions (Plutchik [1980]).

To provide a full definition of "emotion," it is finally necessary to evoke what "emotion" is not. "Emotion" often appears in a dichotomy with "reason," echoed in the dichotomies reason vs. passion, objective vs. subjective. The subjectivity of emotions an individual can go through thus contrasts with the alleged objectivity of facts and figures.

As emotions are intrinsically subjective, addressing the question of emotions, and especially the purported effect of language on emotions, requires the utmost caution from the analyst.

\subsubsection{Loaded words}

Many terms describe the ability of a word to convey emotional content: "loaded words," "emotionally-charged words," "emotion-laden words," or "emotive words." First, it is necessary to distinguish between "emotion words" and "emotive words." "Emotion words" can simply be defined as the words referring explicitly to emotions such as anger, sadness, or joy. As Charaudeau [2008: 51] explains, these words might not to be the most effective device to elicit those emotions. "Emotive words," however, can be defined as words that trigger an emotional response in the audience and influence their perception of reality (Walton \& Macagno [2014: 2, 5]). Words are thus seen as having an implicit argumentative value that can be used by the speaker to influence the addressee:

In our words we can conceal an implicit change of our interlocutor's knowledge or a

silent alteration of his system of values. (Walton \& Macagno [2014: 1])

The authors base their study on Stevenson's account of emotive words and the persuasive power of definitions. Stevenson $[1937,1944]$ highlights the emotional content of words and shows the ability of words and definitions to provide an implicit evaluation of reality.

Macagno \& Walton further distinguish between "dependent" and "independent" emotive words [2014: 38]. The first refers to words whose literal meaning has an emotional charge (such as "war," "peace," "death," or "terrorist" [2014: 5]) while the latter qualifies words that take on an emotive value when they are used (for example, "dead" compared with "deceased," or "steed" compared with "horse" [2014:39]). The term "loaded lexicon" seems to be used as a synonym for "emotive words" as it also refers to the evaluative power of words, i.e. their capacity to deliver a judgment on reality.

29 At this point, some questions can be raised: which words fall into that category? What evaluation of reality do they convey? More precisely, what argumentative conclusion do they support? Furthermore, to what extent does it rely on the context in which the word is to be found? Finally, to what extent is loaded language persuasive? As a corollary, how can we measure the impact of a word? 


\section{Overview of the lexical patterns in the corpus}

30 performed with the concordance program and text parser Sketch Engine ${ }^{7}$. I shall first offer an overview of the key-words and lexical patterns identified in the corpus thanks to Sketch Engine, before moving on, in the third part, to the case studies of loaded words, as well as other salient features of the corpus.

\subsection{Brief presentation of the corpus and Sketch Engine}

The corpus under study is taken from the Congressional Record. The speeches, dealing with the question of drug reform in the United States - more specifically, the opioid crisis and the legalization of marijuana - span over a year (from January 2017 to January 2018). The corpus contains a total of thirteen speeches, for a total of 20,658 words (i.e. 146 minutes of speech). These speeches were delivered by eighteen representatives: fifteen men and three women; thirteen Republicans and five Democrats.

To get an overview of the lexical patterns found in the corpus, I used Sketch Engine. It is a parsing tool that can give the typical combinations for a word (called "word sketch"), extract key-words and generate lists of the most frequent words in the corpus under study. The word sketch gives the collocational and grammatical behavior of a given word based on its occurrences in the corpus under study: for example, the words that modify it, the type of objects it takes (for a verb), or the words with which it coordinates. The keywords are defined as words that appear more frequently in the focus corpus than in the reference corpus. Finally, the word list is ordered depending on the number of occurrences of the lemma in the corpus. The more occurrences it has, the higher rank it gets.

\subsection{An overview of the most frequent words}

I would like to briefly present the most represented words in the corpus to give an overview of the lexical fields as well as the types of loaded words frequently used. This will provide a basis for the qualitative study presented in the third part of this paper.

In the fifty most frequent nouns, we can, unsurprisingly, find words in the semantic fields of drugs ("marijuana" (146), "opioid" (44), "heroin" (23), "cannabis" (29), "addiction" (53), "overdose" (48)), health ("treatment" (44), "patient" (25), "doctor" (22), "prescription" (35)) and legislation ("state(s)" (137), "government" (49), "policy" (39), "act" (27), for example).

In the list, many words can be referred to as "loaded words" and have a negative connotation: "problem" (53), "issue" (31), referring to the phenomenon: "epidemic" (31), "crisis" (21) (the opioid epidemic / crisis), or its consequences: "addiction" (53), "overdose" (48), "pain" (34), and "death" (31). The verb "die" is also one of the fifty most used verbs (17 occurrences).

Among the most frequent adjectives we can identify adjectives referring to the different uses of marijuana or other drugs: "medical" (42), "criminal" (6), "recreational" (6), or also, "illegal" (28), "legal" (14). Some adjectives have a negative connotation and can potentially trigger emotions: "dangerous" (10), "devastating" (7), while others stress the 
importance or force: "powerful" (7), "important" (22). Finally, some adjectives convey the judgment of the speaker ("ethical words," Stevenson [1937, 1944]): "good" (17), "great" (16), "positive" (9) and "bad" (9).

Two of the most frequent adverbs refer explicitly to feelings "tragically" (7), "unfortunately" (5) and can thus be defined as "emotion words".

Besides being used to retrieve the most frequently used words, Sketch Engine was also used to analyze collocations and examine the context of the loaded words thanks to the concordancer. I would like to present the results through various case studies to try to unveil the mechanisms behind the appeals to emotions.

\section{Case studies}

In the corpus, different emotive words can be identified. First, I shall study some examples of "dependent emotive words": "cancer," "death," "danger," and "addiction," before moving on to the "independent emotive words" that generate a category and whose mechanism is thus similar to an argument from classification.

\subsection{The evocative power of loaded words}

\subsection{1. "We are in a crisis mode" 8 : "danger," "risk," and other red-flag words}

In the corpus under study, many words evoke the RISK frame: "danger" and derivatives ("danger," "endanger," "dangerous," 19 occurrences), as well as "risk" ("at risk," "run the risk," "increase the risk") and other related words.

The RISK frame is defined by Fillmore \& Atkins in a seminal paper [1992] and, more recently, on the lexical database FrameNet ${ }^{9}$. The lexical units evoking this frame include terms such as "peril," "hazard," or "threat." Fillmore \& Atkins describe chance (defined as "the uncertainty about the future," 81) and harm (defined as "a potential unwelcome development," 82) as the two notions at the core of the RISK frame [1992: 80]:

The choice and possibilities, and the negatively and positively valued alternative outcomes, make up part of the basic scenarios associated with RISK. (Fillmore \& Atkins [1992: 81])

On the lexical database FrameNet, multiple frames involve the concept of RISK: "run_risk," "being_at_risk," "risky_scenario," and "risky_situation". The Being_at_risk frame seems to be the most relevant to study the cases identified in the corpus:

Being_at_risk frame:

Definition: "An asset is in a state where it is exposed to or otherwise liable to be affected by a Harmful_event which may be metonymically evoked by reference to a Dangerous_entity. Words expressing relative safety (i.e., lack of risk) are also in the frame. ${ }^{10}$

41 From this definition, and the careful examination of the occurrences of "danger" (and "risk") in the corpus, we can identify the following components as being understood in the RISK frame:

Asset ("something judged to be desirable or valuable which might be lost or damaged") = health, life;

Harmful_event ("an event that may occur or a state which may hold which could result in the loss or damage to the Asset") = drug use, drug abuse; 
Dangerous_entity ("a concrete or abstract entity which may come to cause the loss of, or damage to the Asset either due to its participation in a Harmful-event") = drugs;

Bad_outcome ("risky_scenario" frame) = addiction, cancer, mental diseases, or, eventually, death.

Uncertainty and potential harm are two components that fuel fear and anxiety. The use of "danger" and related lexical units thus potentially activates this frame and participate in a strategy of fearmongering.

(1) Marijuana use increases the risk of cancer, hinders brain development in adolescents and young adults, and encourages experimentation with even more dangerous drugs, including opioids. (Mr. Harris, \#9) ${ }^{11}$

(2) We have to make sure that we also understand, for those out there trying to legalize marijuana, I caution you, because the marijuana that is out there on the streets or presented in many areas can cause tremendous psychiatric problems for those who are already at risk. The longer you are on some of the types of marijuana, the greater risk you have for things like delusional behavior. (Mr. Murphy, \#6)

In the first example, the term "risk" is used in what seems to be a restatement of a scientific study, even though no source is mentioned. "Risk" being associated with the direct object "cancer" and with the verb "increase" thus indicates a high propensity for cancer. In the second example, "risk" is found in a correlative structure that associates the consumption of marijuana with a higher risk of delusional behavior. It is used with a performative verb ("I caution you"). The two examples are generic sentences; the first one does not mention the drug user while the second one uses "you," therefore involving the audience. These threats are thus mentioned in order to argue against the use of marijuana.

This is reinforced by the use of intensifiers: "extremely dangerous drugs," (Mr. Chabot, \#6), "highly addictive," and "even more dangerous drugs" (Mr. Harris, \#9), as well as the use of adjectives stressing the importance and the urgency of the matter: "in imminent danger of harming themselves" (Mr. Murphy, \#6), "serious problem” (Ms. Gabbard, \#4), “ severe negative consequences" (Mr. Rohrabacher, \#2), “tremendous psychiatric problems" (Mr. Murphy, \#6), “terrible news” (Ms. Kaptur, \#6). More than informing and warning, the goal is here to elicit fear and anxiety in order to act upon the beliefs and actions of the audience.

Some speakers draw an apocalyptic portrait of the situation: the expression "wreak havoc" is used three times, "destruction" and derivatives ("destructive," "destroy," and "destroyer"), "devastate" ("devastating impact," "devastating effects") or "appalling." Here is a case in point:

(3) Opioid abuse is wreaking havoc on our homes, our schools, our churches. Its devastating effects are destroying our families and the lives of our loved ones. (Mr. Gallagher, \#6)

With the subject of the first sentence, the enemy is identified as the cause of a terrible catastrophe (with the use of the hyperbolic expression "wreaking havoc") while the victims are identified with the objects presented in a ternary structure: "our homes, our schools, our churches." The allusion to children (through the mention of "schools") is used to elicit empathy. The second sentence insists on the catastrophic nature of the event: "devastating effects," "destroying," and once again the speaker arouses 
compassion with the mention of the "families" and the "loved ones." The deictic used when identifying the victims of this scourge ("our") creates a category where the legislators and the citizens are both included.

\subsubsection{The addiction trap}

When it is mentioned, addiction is often personified or presented as a trap in which it is quite easy to fall:

(4) They have witnessed patient after patient fall into the traps of addiction.

(Mr. Walden, \#6)

(5) it is so easy to slip into addiction (Mr. Murphy, \#6)

(6) the problems that drove people on the path to addiction

(Mr. Blumenauer, \#8)

(7) allowed the addiction genie out of the bottle (Mr. Blumenauer, \#8)

Once caught in this trap, there seems to be no escape:

(8) those families who are tragically caught up in this addiction (Mr. Walden,

\#6)

(9) help the people break the cycle of addiction. (Mr. Blumenauer, \#8)

(10) they were trapped by these powerful forces (Mr. Blumenauer, \#8)

(11) if not for powerful forces beyond their control (Mr. Blumenauer, \#8)

By presenting addiction as a force or a trap, the speakers minimize the importance and role of the individuals, therefore presenting them as victims. In the many instances of storytelling that can be identified (particularly in speech \#6), addiction is used in narratives that can be interpreted as a drama, on the one hand, as they aim at eliciting sorrow and grief, and a cautionary tale, on the other hand, as they act as a warning and cause fear.

Moreover, the identification of the addressee to these stories is made easier by some comments, sometimes found at the end of the story, which stress the common character of the crisis, which appears all too familiar:

(12) These types of stories are becoming all too common. (Mr. Chabot, \#6)

(13) It doesn't pick people because of their race, age, or socioeconomic status. We all know someone impacted by the opioid epidemic. It has literally touched every corner of our country and every community in our States. (Mr. Walden, \#6)

(14) Again, most of us know someone, a family member, a friend, a neighbor, who has been impacted by this epidemic in some way. (Mr. Bucshon, \#6)

51 This representation also allows to implicitly reconstruct a chain of events:

opioid use > addiction $>$ overdose $>$ death

And in the cases where marijuana is recategorized as a gateway drug:

marijuana use $>$ opioid use $>$ addiction $>$ overdose $>$ death

This simplification in the form of a slippery slope argument thus presents addiction as an unavoidable scourge and a slow descent into hell.

Besides, "addiction" is usually contained in the frame of the "war on drugs" metaphor, where we can identify the following conceptual networks:

DRUGS ARE THE ENEMY.

DRUG ADDICTION IS A BATTLE. 
(15) We miss a chance to win the war against opioid death and addiction

(Mr. Blumenauer, \#12)

(16) Since its inception, this Office has played a central and critical role in fighting drug trafficking and drug addiction (Mr. Rothfus, \#6)

(17) In her decades-long battle with this addiction-trying to get off of this addiction-she was forced to travel more than 5 hours into Washington State just to find a provider who could help her with Suboxone and get off of her addiction. (Mr. Walden, \#6)

(18) Of the 27 million Americans suffering from addiction, less than 1 percent receive evidence-based treatment. (Mr. Murphy, \#6)

(19) "recovering from addiction," "an addiction disorder"

By transfer, opioid abuse is recategorized as a "disorder," here in a speech delivered by a representative who is also a physician (therefore implicitly being an argument from expert opinion):

(20) The opioid abuse disorder and drug addiction have impacted every community in our Nation. (Mr. Bucshon, \#6)

\subsubsection{The c-word and the prevalence of death}

rdinary and familiar language, "cancer" is sometimes referred to as the "c-word"13 showing that it has become a taboo topic in our society. Cancer indeed represents one of the great evils of our modern world. As such, mentioning it would be expected to provoke a great impact.

In the corpus under study, only three occurrences of the word "cancer" can be identified. However, what is worth pointing is that it can be evoked to argue in favor of two opposite argumentative conclusions, i.e. for or against the legalization of marijuana:

(21) But despite these frightening statistics, State and Federal lawmakers across the country are still pushing to legalize recreational marijuana. Marijuana use increases the risk of cancer, hinders brain development in adolescents and young adults, and encourages experimentation with even more dangerous drugs, including opioids. (Mr. Harris, \#9)

(22) So as we look at ways that we need to update our outdated drug policies and the need for us to reform a very broken criminal justice system, we need to take into account the growing body of evidence that suggests the medicinal benefits of marijuana, including, preventing epileptic seizures, reducing anxiety, and even halting the growth of cancer cells. (Ms. Gabbard, \#4)

In the first example, cancer is presented as a potential consequence of marijuana use ("Marijuana use increases the risk of cancer") while in the second example, it is said that the growth of cancer cells can be halted thanks to medicinal marijuana. One possible explanation is the ambiguity linked to the word "marijuana" which can refer to different substances such as CBD (cannibidiol) or THC (tetrahydrocannabinol).

Furthermore, death seems omnipresent: the noun "death(s)" appears 31 times, the verb "die(d)" 17 times, the adjective "dead" 1 , and the adjective "deadly" 4 times. Beside those 
occurrences, death is mentioned indirectly, through euphemisms. Here are some examples:

(23) We are much better off working hand in hand to pass legislation that changes issues than standing next to each other as pallbearers for another 59,000 people in our Nation next week. (Mr. Murphy, \#6)

(24) In her case, it was an overdose that finally took her life-another important reason why we have to deal with this 42 C.F.R. and get rid of that arcane and, quite frankly, deadly law. (Mr. Murphy, \#6)

(25) On several occasions, it has had to break the terrible news to these children that their parents succumbed to their addiction. (Mr. Carter, \#6)

(26) Because headline after headline reminds us of the tragic loss of life that has resulted from our Nation's opioid and addictions risk, we have to step up.

We have to take action. (Mr. Gallagher, \#6)

The noun "life" (30 occurrences) is also present but it is mostly associated with verbs that have a negative connotation ("hurt," "lose," "damage," "ruin," "destroy," and "affect") or that refer to control and the notion of responsibility ("control," "micromanaging," "intrude," "People need to be responsible for their own lives."). Only 5 of the 30 occurrences of "life" have a positive connotation and among these 5 occurrences ("turn their lives around," "save lives," "bring them back to life"), only 4 really contribute to delivering a message of hope.

Figure 1: Word sketch of the noun "life" (Sketch Engine) as used in the corpus under study

life as noun $30 x$

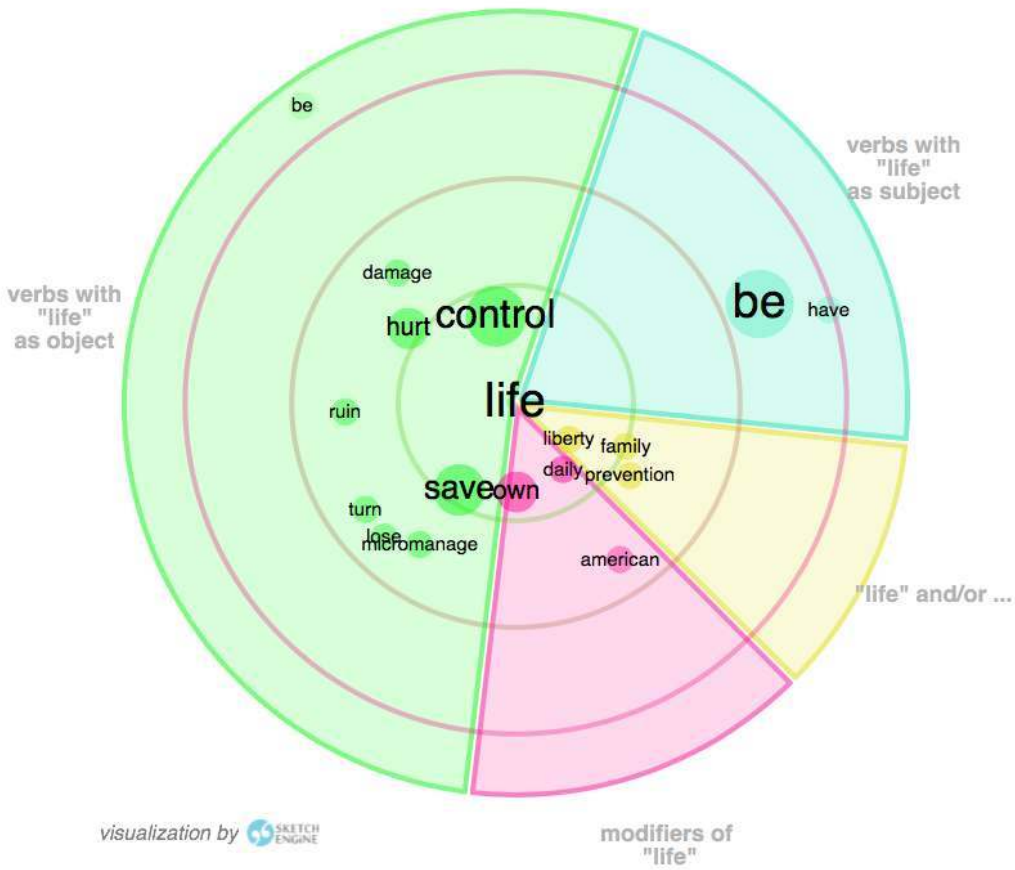

(27) Sadly, this young man would not survive his addiction. He died from heroin. It devastated the family and stole another American in the prime of his life. This story is repeated all too often. (Mr. Walden, \#6) 
60

excerpt is an example of storytelling used as an appeal to pity. The emphasis clearly lies on the emotions, with the use of the adverb "sadly" (emotion word) that conveys the stance of the speaker and the three references to death in only three sentences ("not survive," "died," "stole another American in the prime of his life". The ineluctability of the outcome is conveyed by the use of the modal "would," echoing the slippery slope argument (the outcome was to be expected). Storytelling and dramatization are once again used to arouse compassion. Finally, the conclusion of the story opens towards a generalization, showing that this case is just an instance among many others. casualties is compared to that of large-scale tragedies, be it everyday tragedies such as car accidents or historical tragedies such as the Vietnam War.

(28) The epidemic has hit close to home in my home State of Oregon, where more people now die from drug overdoses than from deaths in automobile accidents. (Mr. Walden, \#6)

By mentioning car accidents, which are a very common and familiar everyday tragedy, the speaker is trying to elicit pity, sadness and fear. The stress is clearly laid on emotion as neither figures nor evidence are provided.

(29) We have now reached a point where we will have more deaths from drug overdoses this year than there are names on the Vietnam Veterans Memorial Wall in Washington. That is a frightening concept. (Mr. Murphy, \#6)

In this example, the speaker is exploiting the American collective unconscious to arouse empathy: the Vietnam War is an event in the history of the United States that still has a very strong emotive potential. By mentioning the Vietnam War, he is also drawing on notions such as patriotism in order to arouse a feeling of togetherness.

This overrepresentation of the lexical field of death and indirect references to death point to a large reliance on appeal to emotion, more specifically, appeal to pity. This is reinforced by the frequent use of storytelling and the process of dramatization in order to inspire empathy.

What seems important to underline is that the same rhetoric is (re)used to argue in favor of the opposite argumentative conclusion:

(30) Yet despite the well-documented death and destruction permeated by organized crime, the two groups who are most tragically harmed by the Federal Government's intransigence - it is not necessarily the groups that they are trying to save, but, in reality, they are trying to save these people. They are putting them in jail. They are destroying people's lives in that way, but they are also victimizing American seniors and our veterans - yes, our veterans. (Mr. Rohrabacher, \#2)

In this example, the exact same words are used to refer, this time, to the government's acts instead of referring to the terrible consequences of drug use.

\subsection{The insidious force of categorization}

Lakoff \& Johnson emphasize the significance of categorization in the human conceptual system: 
A categorization is a natural way of identifying a kind of object, or experience by highlighting certain properties, downplaying others, and hiding still others. (Lakoff \& Johnson [1980: 163]) this drug:

A well-known example of the potency of categorization is the emotive conjugation attributed to Bertrand Russell:

I am firm; you are obstinate; he is a pig-headed fool.

This example shows that by simply selecting the appropriate term, the speaker can depict the same reality in very different ways, either presenting it in a truly positive light, or, on the contrary, offering a quite negative perspective.

Well-known examples in politics of loaded words that impose a certain categorization include the term "pro-life" and "pro-choice" (Macagno \& Walton [2014: 2]), "tax relief" (Lakoff [2003]) and, as part of the green rhetoric, the collocation "clean energy" (illustrating the "greenwashing" process described by Bonnefille [2008; 2013]). These terms are identified by Macagno \& Walton as a subcategory of "emotive words": "independent emotive words" [2014: 38].

When it comes to drug reform, in the corpus under study, it is interesting to investigate the categorizations induced by a) the terms referring to legislation, b) the terms and phrases designating marijuana, as well as c) the phrases evoking the potential users of

a) "legalization," vs. "decriminalization," and "prohibition";

b) "marijuana," "cannabis," "medical marijuana," "a weed," "a dangerous gateway drug";

c) "responsible adults," "senior citizens," vs. "our youth," "our young people," "adolescents and young adults," "our Nation's children".

\subsection{1. "legalization," “decriminalization," and "prohibition"}

While "legalization" could be described as a neutral term, "decriminalization" can be considered a loaded word since it offers a biased perspective on the issue. It is indeed used in contexts where the speaker pushes for cannabis policy reform at the federal level:

(31) Mr. Speaker, I am rising today to urge my colleagues to support H.R. 1227, the Ending Federal Marijuana Prohibition Act, [...] where we are seeking to address our outdated and widely problematic marijuana laws by federally decriminalizing marijuana. (Ms. Gabbard, \#4)

It should be noted that this motif is at the core of Ms. Gabbard's rhetoric, as it is repeated all through her speech:

(32) Our current laws are turning the everyday Americans into criminals.

(Ms. Gabbard, \#4)

(33) So, rather than actually helping people, our current laws are turning them into criminals, forever impacting their future and the future of their families. (Ms. Gabbard, \#4)

(34) So whether you personally think that marijuana use is good or bad, whether you would choose to use marijuana or not, the question is: Should we really be sending people to jail and turning them into criminals for it? The answer is no. (Ms. Gabbard, \#4)

Through an emphasis on criminalization, the speaker points to the flaws of the federal drug policy. She blames the federal government for "turning the everyday Americans 
into criminals." In the third excerpt, which appears towards the end of her speech, she reframes the debate and corners the audience with a false question, leaving then just one possible answer: decriminalization.

It must be noticed that once again, the speaker appeals to pity, evoking the impact on the future of "everyday Americans" and their families, presenting them as victims of the system. While the argumentative conclusion is different from those mentioned in previous analyses, the rhetoric strategies prove to be similar: the processes of victimization and dramatization aim at eliciting compassion.

The term "prohibition" is also a loaded word that is used when arguing in favor of the respect of states' marijuana laws ${ }^{14}$. It offers a biased view in the sense that (i) it lays emphasis on the strict enforcement of restriction by the federal government, (ii) it also alludes to a historical period that is ingrained in the collective memory of the United States, and thus enables to activate an analogy where the consumption of cannabis is compared to the consumption of alcohol. Therefore, it implicitly opens the door to an argumentative path: why would marijuana be prohibited while alcohol has similar disastrous consequences and is legal? This is the underlying argumentation of the Bill put forward by Polis ("Regulate Marijuana like Alcohol Bill").

Rohrabacher also relies on a similar rhetoric in his speech where responsibility and freedom are center stage. He uses the term "prohibit" and derivatives ten times in his speech (\#2, "Federal Marijuana Policy") and emphasizes the disastrous consequences of the federal policy:

(35) Today, the scourge of marijuana prohibition has fueled organized crime here and south of our border and in our inner cities and throughout the world. (Mr. Rohrabacher, \#2)

The criminalization is attributed to the federal drug policy thanks to the verb "fuel" that denotes a causal relation ("sustain"). Blumenauer also resorts to this motif in order to show that the efforts of the government are misplaced:

(36) We have spent over $\$ 1$ trillion on a failed war on drugs that concentrates on prohibition and punishment instead of treatment, which would help people break the cycle of addiction. (Mr. Blumenauer, \#8)

\subsection{2. "marijuana," "cannabis," “a weed," “an addictive gateway drug"}

In the speech aforementioned, Rohrabacher calls "marijuana" several times "a weed" in order to dedramatize and soften the impact of the word "marijuana" so as to argue against the federal regulation of marijuana:

(37) Once such failed policy has been the U.S. Government spending billions of dollars and wasting the time of Federal employees - hundreds of thousands, if not maybe tens of thousands of Federal employees - in order to prevent adults from smoking a weed, marijuana. (Mr. Rohrabacher, \#2)

Through the use of this term, Rohrabacher trivializes the use of marijuana. As a result, the trivial, ordinary act of "smoking a weed" contrasts with the response of the government - spending hyperbolic amounts of money ("billions of dollars") and wasting time - making it look completely disproportionate. 
At the other end of the spectrum, Mr. Harris refers to marijuana as "an addictive gateway drug":

(38) Mr. Speaker, with the opioid crisis our Nation is currently fighting, why on Earth should we increase access to an addictive gateway drug?

(Mr. Harris, \#9)

Through a recategorization, Harris presents cannabis as a gateway drug, i.e. he claims that it inevitably leads to the use of stronger drugs, making himself guilty of the slippery slope fallacy. The process of recategorization being bulldozed through the use of the expression as a paraphrase for "cannabis," this implicit premise cannot be called into question.

81 To sum up, by classifying cannabis under this category, he imposes an inference that leads to the argumentative conclusion that cannabis should not be used. The second implicit argumentative conclusion is that the legislators should not push for its legalization.

\subsection{3. "responsible adults" vs. "our Nation's children"}

82 The denomination of the potential users also reveals a particular standpoint on the use of cannabis.

For Rohrabacher, as well as for Polis, who both push for a reform of the federal policy on cannabis, the use of cannabis seems to be a question of responsibility:

(39) States like Colorado, and now dozens of other states, have proven that allowing responsible adults to legally purchase marijuana, gives money to classrooms, not cartels; creates jobs, not addicts; and boosts our economy, not our prison population. (Mr. Polis, \#10)

(40) People need to be responsible for their own lives. That is what freedom is all about, and that is when people will start being more careful about what they do. (Mr. Rohrabacher, \#2)

The notion of "responsible adults" clashes with a well-known stereotype, which is very common when it comes to drug use: the "pothead" or "stoner"15. In the corpus, the emphasis on "responsible adults" contrasts with the mention of the children and families to depict the damage inflicted by drugs:

(41) And, most importantly, we must ensure these drugs are not falling into the hands of our Nation's children. (Mr. Newhouse, \#6)

(42) My colleagues in Congress and I are committed to combating this epidemic to keep it from causing further harm to our Nation's families and communities. (Mr. Newhouse, \#6)

Children are portrayed as either direct potential victims of drugs or collateral victims of the addiction to opioids:

(43) Marijuana use increases the risk of cancer, hinders brain development in adolescents and young adults, and encourages experimentation with even more dangerous drugs, including opioids. (Mr. Harris, \#9)

(44) The stories just keep coming. A story of the mother who lost her $10^{\text {th }}$ child, her youngest child, to this epidemic, who insisted that the words "damn heroin" be put in her son's obituary. Or the couple we learned about 
before Christmas, who overdosed, and 3 days later their infant died from neglect, all three being found 4 days after that. (Mr. Rothfus, \#6)

(Beard [2000], Charteris-Black [2005], Digonnet [2014], to mention a few examples). Metaphors can have several functions: aesthetic, explanatory or persuasive.

In the corpus under study, mainly two metaphors transpire: the "war on drugs" metaphor and the "opioid epidemic" metaphor. I would like to analyze the function of these two metaphors in the corpus under study: How do they participate to an argumentative strategy? Are the metaphors used in the corpus under study lexicalized or creative?

\subsubsection{The "war on drugs" metaphor}

The "war on drugs" metaphor is not a new metaphor as it has been used in many political speeches since Nixon (1971) and can thus be considered a political motif.

It is part of a larger conceptual metaphor: POLITICS is WAR (Lakoff [1991]). This metaphor also includes the well-known "war on terror" metaphor. If we look up the number of occurrences in the COCA, "war on terror" is literally mentioned 2420 times and "war on terrorism" 1454 times while "war on drugs" (and related expressions: "war on narcotics," etc.) amounts to 944 occurrences. This metaphor is evoked through the use of lexicon such as "battle," "fight," "combat," to name a few examples.

The use of this metaphor activates the relief frame, which can be defined as including the following components:

The relief frame is an instance of a more general rescue scenario in which there is a hero (the reliever), a victim (the afflicted), a crime (the affliction), a villain (the cause of affliction) and a rescue (the relief). The hero is inherently good, the villain is evil and the victim after the rescue owes gratitude to the hero. (Lakoff [2003])

The "war on drugs" metaphor can thus be analyzed through the following mappings: DRUGS ARE THE ENEMY / THE VILLAIN.

AMERICAN CITIZENS ARE THE VICTIMS.

DRUG ADDICTION IS A BATTLE / A STRUGGLE.

This metaphor is realized in different ways in our corpus:

(45) I have met with community leaders, first responders, doctors, police officers, patients, and those on the front lines of this fight against opioid addiction." (Mr. Walden, \#6)

(46) As a physician, I have seen the power of addiction up close and have focused on shaping real policy solutions here in Washington, D.C., to improve access to treatment for patients who are battling their problem every day. (Mr. Murphy, \#6)

(47) I heard from Oregonians who have struggled with the epidemic 
themselves. (Mr. Walden, \#6)

(48) We need to combat the illicit drugs coming into this country as well as equip doctors, nurses, and first responders with the resources they need to treat pain appropriately. (Mr. Newhouse, \#6)

(49) While CARA will give local law enforcement and healthcare officials more resources to fight opioid addiction, we need additional legislation to help combat the importation into the United States of extremely dangerous synthetic drugs like fentanyl and carfentanil, which many have blamed for the spike of heroin overdoses. (Mr. Chabot, \#6) can be focused on more specific aspects, such as the importation of illicit drugs (eg. $3 \& 4$ ). However, in other occurrences of the metaphor, other villains can be identified:

- "bad actors from China and India" who export illicit drugs:

(50) Designed to stop dangerous synthetic drugs like fentanyl, which you heard about, and carfentanil from being shipped through our borders, this legislation will combat bad actors from China and India who have been taking advantage of weaknesses in international mail security standards to break U.S. customs laws and really wreak havoc on our communities. (Mr. Newhouse, \#6)

91 - different entities and agents who are blamed for the current situation:

(51) It was a public policy failure of government, the industry, and, sadly, some unscrupulous practitioners that allowed the addiction genie out of the bottle. (Mr. Blumenauer, \#8)

92

Identifying the culprits creates the opportunity to channel and direct the blame at specific entities for the problem at stake and gives a misleading impression of manicheism while the reality is more complex.

At some point, the metaphor is made explicit thanks to a comparison:

(52) It is like trying to fight a war without soldiers, trying to fight this war, which is killing more people every year than the entire war in Vietnam, but we do not have the soldiers to fight this. (Mr. Murphy, \#6)

This comparison emphasizes the lack of resources needed to engage in the fight and forebodes a failure.

As a battle entails two opposed sides, this metaphor also implies the existence of the soldier, or hero, who is fighting against the enemy, the villain. This hero can implicitly be understood as the lawmaker, as the following examples seem to confirm:

(53) I look forward to working with my colleagues on both sides of the aisle to counter this trend in hopes of saving lives. (Mr. Carter, \#6)

(54) There is more that we can do and we must do in order to save lives.

(Mr. Murphy, \#6)

(55) Mr. Speaker, with that and with some hope that we can pass this legislation and save some lives, I yield back the balance of my time.

(Mr. Murphy, \#6)

(56) America is watching, and now we must act. (Mr. Gaetz, \#6)

It thus reveals the existence of following mapping:

THE LEGISLATORS ARE AMERICAN HEROES. 
The legislators seem to be invested with the mission of defending the citizens of the United States, by engaging in a battle with the enemy (the drugs).

(57) We must fight, we must work together, we must put politics aside. Only then can we begin to heal our Nation from this crisis. (Mr. Chabot, \#6)

(58) The Justice Department is not just on the wrong side of history and the American public, they are missing a chance to cure the damage caused by selective and cruel enforcement of marijuana laws. (Mr. Blumenauer, \#12)

In this example, the expression "heal our Nation" activates another conceptual framework where the legislators are the doctors and the Nation the patient.

Thanks to this intricate narrative, metaphors contribute to the creation of a myth:

[I]n political contexts metaphor can be, and often is, used for ideological purposes because it activates unconscious emotional associations and thereby contributes to myth creation: politicians use metaphor to tell the right story. (Charteris-Black [2011: 28])

97 To sum up, these conceptual metaphors glorify the role of the legislators (heroes and saviors) and their work (a noble mission). More importantly, it also lays the ground for harsh restrictions or drastic measures, in virtue of the topos: "desperate times call for desperate measures."

While the metaphor is originally used to designate the drugs as the enemy, it can also be subverted and reappropriated to serve quite a different argumentative conclusion and criticize the federal policy, as the following example shows:

(59) the Trump administration declared war on State legalization of marijuana (Mr. Blumenauer, \#12)

(60) Sessions and the Trump administration overruled that guidance and declared open war (...) (Mr. Blumenauer, \#12)

This speech was given in response to the decision of President Trump and Attorney General Sessions to repeal the Cole Memo. Thanks to the recycling of the original metaphor, Blumenauer lays the blame on the government and its failed policies.

It should be noted that this metaphor can be associated with the phrase "the wrong side of history," which imposes a manicheist view of the world. This actually makes the issue look much simpler than it actually is. While the combat metaphor artificially distinguishes between two sides (as the Hostile_encounter frame shows), it fails to account for the complexity of the phenomenon and address what is really at stake.

\subsubsection{The "opioid epidemic" metaphor}

1 The "opioid epidemic" metaphor seems to be another very effective instrument to propagate fear. The following questions arise: Why isn't the opioid crisis a real epidemic, in the medical sense of this term? What makes this metaphor possible? How is it realized in language in the corpus under study? How often is this metaphor used? To what ends?

When "epidemic" is used to refer to the opioid crisis, it is used figuratively, since "epidemic" is defined as "a widespread occurrence of an infectious disease in a community at a particular time" (OD). Examples of infectious diseases include, for example, rabies, plague, polio, or more recently AIDS, hepatitis, measles or SARS. However, the figurative use of "epidemic" is quite common as it is recorded in the dictionary, so it can be said to be a conventional metaphor. 
This mapping is made possible by different characteristics of the opioid crisis:

i) it refers to a sudden outbreak;

ii) it represents a massive health crisis;

iii) it is an urgent matter;

iv) it is spread on the whole territory.

In the corpus under study, the term "epidemic" is used 31 times, most occurrences being found in the speech entitled "Opioid Addiction Crisis" (\#6) ${ }^{16}$ :

(61) our Nation is facing an epidemic (Mr. Newhouse, \#6)

(62) Every day, there are more headlines about how heroin and other opioids are basically taking over the country. (Mr. Chabot, \#6)

(63) the opioid epidemic sweeping over our great Nation (Mr. Harris, \#9)

(64) The epidemic has hit close to home in my home State of Oregon, where more people now die from drug overdoses than from deaths in automobile accidents. I have met with community leaders, first responders, doctors, police officers, patients, and those on the front lines of this fight against opioid addiction. (Mr. Walden, \#6)

It is construed either as an imminent threat "has hit close" (evoking implicitly the RISK frame with the main components chance and harm) or a powerful, uncontrollable, unstoppable, uncontainable phenomenon: "taking over," "sweeping over." In most occurrences, it is used along with the "war on drugs" metaphor:

(65) combating this growing epidemic (Mr. Newhouse, \#6)

(66) Combating the opioid epidemic in Oregon and every State of the union is going to require a real bipartisan team effort to continue, from elected officials with the input from healthcare experts and those on the front line of this fight in our local communities. (Mr. Walden, \#6)

(67) That is why, Mr. Speaker, it is imperative that we work together to find new and more successful ways to combat the opioid epidemic. (Mr. Chabot, \#6)

Within the conceptual frame, the opioid epidemic is identified as the common enemy. The purported effects are twofold. First, fighting against a common enemy brings people together and appeals to patriotism. Then, combating the same and only enemy requires the legislators to form a united front: "it is imperative that we work together," "Combating the opioid epidemic [...] is going to require a real bipartisan team effort to continue."

The use of the two metaphors also glorifies the work of the legislators and contributes to construe legislators as American heroes (ethos). They are invested in a very important mission:

(68) It is clear that this is a crisis, which is why we in Congress are committed to combating this growing epidemic. (Mr. Newhouse, \#6)

(69) My colleagues in Congress and I are committed to combating this epidemic to keep it from causing further harm to our Nation's families and communities. (Mr. Newhouse, \#6)

To conclude, this metaphor is used to stress the urgency of the phenomenon, as a call for action, but also to propagate fear. It contributes to the apocalyptic portrait painted by many of the politicians. It also contributes to the ethos of the speakers: the speaker is 
seen as a soldier, a warrior, and as a result, legislators appear as modern American heroes.

When faced with a metaphor, it is necessary to identify the whole frame that is activated in order to understand how it is used and which argumentative conclusion it serves. The metaphors described can be said to be conventional, because their use is recorded in the dictionary. They also happen to be well known and have been used in the political discourse on drug reform. As such, they can be called "worn-out metaphors" (Digonnet [2014]). The question that can thus be asked is: to what extent can a worn-out metaphor be effective?

\section{Conclusion}

110 In this paper, I tried to identify and analyze the different elements that partook in appeals to emotion. In the corpus under study, it appears that storytelling, the use of loaded words, and the use of two conventional metaphors, form the main rhetoric devices to elicit empathy or arouse fear.

111 What also appear to be crucial in the rhetoric are the parts of the described phenomenon that are hidden or silenced by the metaphors and frames chosen. Shedding light on particular aspects of a situation, while leaving others in the dark, allows the speaker to present the multi-faceted phenomena in a way that serves his or her purpose.

112 In these persuasive strategies, presupposition seems to occupy a central role. In order to incept inferences that could be accepted by the audience, the speaker has to rely on the prior knowledge and expectations of the linguistic community and address their preconceptions and their collective unconscious.

When emotions are concerned, it seems that a depiction of the event through meticulously chosen words evoking frames and weaving a web of metaphors is quite effective. Thanks to a carefully crafted mechanism, these silent devices enable the speaker to subtly create an atmosphere of urgency and oppression, either intended as a call for action or laying ground for the acceptance of more restrictive measures.

\section{BIBLIOGRAPHY}

ANSCOMBRE Jean-Claude, 1995a, Théorie des topoï, Paris : Kimé.

ANSCOMBRE Jean-Claude, 1995b, « La théorie des topoï : sémantique ou rhétorique ? ", Hermès 15, 185-198.

ANSCOMBRE Jean-Claude, 2001, "Le rôle du lexique dans la théorie des stéréotypes ", in AMR HELMY I. (ed.), Langages 142, Les discours intérieurs au lexique, 57-76, https://doi.org/10.3406/lgge.2001.883 BEARD Adrian, 2000, The Language of Politics, London \& New York: Routledge. 
BONNEFILLE Stéphanie, 2008, "When green rhetoric and cognitive linguistics meet: President G. W. Bush's environmental discourse in his State of the Union Addresses, 2001-2008”, Metaphorik.de 15, 28-71, http://www.metaphorik.de/index.htm

BONNEFILLE Stéphanie, 2013, “'Energy Independence': President Obama's Rhetoric of a Success Story", Research in Language 11(2), 189-212.

CHARAUDEAU Patrick, 2008, "Pathos et discours politique », in RINN M. (ed.), Émotions et discours, Rennes : Presses universitaires de Rennes, 49-58, https://books.openedition.org/pur/30418 CHARTERIS-BLACK Jonathan, 2005 [2011], Politicians and Rhetoric: the Persuasive Power of Metaphor, Basingstoke \& New York: Palgrave Macmillan.

DIGONNET Rémi, 2014, “Power and Metaphor”, Lexis 8, http://journals.openedition.org/lexis/224

FILLMORE Charles J. \& ATKINS Beryl T., 1992, “Toward a Frame-Based Lexicon: The Semantics of RISK and its Neigbors", in LEHRER A. and KITTAY E. (eds.), Frames, Fields and Contrasts: New Essays in Semantic and Lexical Organization, Hillsdale: Erlbaum, 75-102.

LAKOFF George \& JOHnSon Mark, 1980, Metaphors We Live By, Chicago: The University of Chicago Press.

LAKOFF George, 1991, "Metaphor and War. The Metaphor System Used to Justify War in the Gulf", Peace Research 23(2), 25-32.

LAKOFF George, 2003, "Framing the Dems," The American Prospect.

LAKOFF George, 2004, Don't Think of an Elephant! Know your Values and Frame the Debate. White River Junction, Vermont: Chelsea Green Publishing.

MACAGNO Fabrizio \& WALTON Douglas, 2010, "What we hide in words: emotive words and persuasive definitions", Journal of Pragmatics 42, 1997-2013.

MACAGNO Fabrizio \& WALTON Douglas, 2014, Emotive Language in Argumentation, New York: Cambridge University Press.

PETRUCK Miriam R. L., 1996, “Frame Semantics,” Handbook of Pragmatics 2.

PLANTIN Christian, 1998, « Les raisons des émotions », in BONDI M. (ed.), Forms of Argumentative Discourse / Per un'analisi linguistica dell'argomentare, Bologne : CLUEB, 3-50.

PLUTCHIK Robert, 1980, A General Psychoevolutionary Theory of Emotion, New York: Academic Press. STEVEnson Charles L., 1937, “The Emotive Meaning of Ethical Terms,” Mind 46(181), 14-31.

STEVEnSON Charles L., 1944, Ethics and Language, New Haven, CT: Yale University Press.

TANNEN Deborah, 1979, “What's in a Frame? Surface Evidence for Underlying Expectations”, in FREEDLE R. (ed.), New Directions in Discourse Processing, Norwoord, NJ: Ablex.

\section{References}

[SEP] The Stanford Encyclopedia of Philosophy. SCARANTINo, Andrea \& DE SOUSA, Ronald, "Emotion", The Stanford Encyclopedia of Philosophy (Winter 2018 Edition), Edward N. Zalta (ed.), URL = <https:// plato.stanford.edu/archives/win2018/entries/emotion/>.

[OED] The Oxford English Dictionary. "emotion, n." OED Online, Oxford University Press, www.oed.com/view/Entry/61249. Accessed 30 October 2018.

[OD] The Oxford Dictionary. "post-truth" Oxford Dictionaries Online, Oxford University Press, https:// en.oxforddictionaries.com/definition/post-truth. Accessed 30 October 2018. 


\section{Tools and corpora}

Drug reform in the Congressional Record (January 2017-January 2018). Personal corpus.

COCA (Corpus of Contemporary American English). https://corpus.byu.edu/coca/

Frame Net. https://framenet.icsi.berkeley.edu/fndrupal/framenet_search

Sketch Engine. https://www.sketchengine.eu/

\section{NOTES}

1. The Oxford Dictionary, https://en.oxforddictionaries.com/word-of-the-year/word-of-theyear-2016

2. "Relating to or denoting circumstances in which objective facts are less influential in shaping public opinion than appeals to emotion and personal belief." ("post-truth," The Oxford Dictionary, https://en.oxforddictionaries.com/definition/post-truth)

3. «Le sens d'un mot n'est rien d'autre que le faisceau de topoï attaché à ce mot » (Anscombre [1995b: 91]).

4. «Le stéréotype d'un terme est une suite ouverte de phrases attachées à ce terme, et en définissant la signification » (Anscombre [2001: 60]).

5. «Une communauté linguistique sera tout ensemble de sujets parlants qui est présenté comme partageant (entre autres choses) une certaine liste de termes affectés des mêmes significations » (Anscombre [2001: 60]).

6. https://framenet.icsi.berkeley.edu/fndrupal/WhatIsFrameNet

7. http://sketchengine.eu

8. This quotation is taken from the corpus (Mr. Murphy, \#6).

9. FrameNet is a project that builds a lexical database based on the annotation of authentic examples. For each frame, a definition is provided, as well as the Frame Elements (FE) and their syntactic realization (valence patterns). https://framenet.icsi.berkeley.edu/fndrupal/about

10. https://framenet2.icsi.berkeley.edu/fnReports/data/frameIndex.xml?frame=Risk_scenario

11. After each example, I shall provide the name of the speaker and the number of the speech as numbered in the corpus I constituted. In the examples, the underlined segments and bold type are mine.

12. "[Addiction] is regarded by many as a discrete disease entity, a debilitating disorder rooted in the pharmacological effects of the drug, which is remorselessly progressive" (WHO, http:// www.who.int/substance_abuse/terminology/who_lexicon/en/)

13. Even though it should be noted that this expression most commonly refers to the four-letter expletive.

14. A quick look at the examples listed in The Oxford Dictionary seems to confirm this hypothesis, as they are all used in a similar context: https://en.oxforddictionaries.com/ definition/prohibition

15. For example, the characters Debbie and Dank portrayed in the series Disjointed embody the stereotype of the "pothead."

16. It should be noted that the speech \#6 is the longest speech in the corpus (10,348 words, i.e. 60 minutes). Many speakers (11, to be specific) take the floor and their speech is mostly characterized by instances of storytelling. 


\section{ABSTRACTS}

The last few years have seen the emergence of the term "post-truth" to characterize the political scene. This concept refers to a situation where the objective facts have far less importance and impact than appeals to emotion and personal belief in order to influence public opinion. In this so-called post-truth era, to what extent can this prevalence of emotions be observed in recent political speeches? More precisely, is lexicon prone to arouse emotions? Through the study of a corpus on the topic of drug reform in the United States, the author examines the participation of loaded words to fearmongering strategies and appeals to pity.

Ces dernières années ont vu l'émergence du terme " post-vérité » pour décrire la scène politique. Ce concept renvoie à une situation dans laquelle les faits ont moins d'importance et un plus faible impact que les émotions et les croyances personnelles pour influencer l'opinion publique. Dans notre ère caractérisée de post-vérité, dans quelle mesure peut-on constater la prédominance des émotions dans les discours politiques récents ? Plus précisément, comment le lexique participe-til à des stratégies visant à éveiller la peur ou susciter la pitié de l'auditeur ? À travers l'étude d'un corpus portant sur la réforme des substances psychoactives aux États-Unis, l'auteur examine le rôle du lexique dans les appels aux émotions.

\section{INDEX}

Mots-clés: lexique des émotions, appel aux émotions, argumentation, persuasion, discours politique

Keywords: loaded words, appeal to emotion, argumentation, persuasion, political discourse

\section{AUTHOR}

\section{SARAH BOURSE}

University Toulouse 2 - Jean Jaurès sarah.bourse@univ-tlse2.fr 